\title{
MEGALOBLASTIC ANAEMIA OF PREGNANCY AND THE PUERPERIUM
}

\author{
By J. W. B. Forshaw, M.A., M.D.(Camb.), M.R.C.P. \\ Senior Medical Registrar, Royal Southern Hospital, Liverpool, 8
}

Megaloblastic anaemia of pregnancy and the puerperium has been regarded as relatively uncommon. For instance, Thompson and Ungley (195I) collected a series of 45 cases during a period of 17 years, and Clarke (1952) saw I5 cases at the Edinburgh Simpson Memorial Maternity Pavilion over a period of $7 \frac{1}{2}$ years, during which time there was a total of 31,755 obstetric admissions. More recently a higher incidence has been reported; at the Royal Victoria Maternity Hospital, Montreal, i 8 cases were seen during a period of three years (Lowenstein, Pick and Philpott, 1955) and at the Rotunda Hospital, Dublin, I4 cases were seen in one year, an incidence of one case in every 288 pregnant women (Lillie, Gatenby and Moore, 1954).

In a previous paper (Forshaw, Jones, Chisholm and McGinley, 1957) we reported an incidence of one case in approximately every 190 confinements at Whiston Hospital. We suspected, however, that the diagnosis had been missed in a number of cases, and that the actual case incidence was considerably higher. We have attempted, therefore, to determine the true incidence of the disease by carrying out a full blood count with estimation of the absolute values on all women in the last trimester of pregnancy or in the puerperium with a haemoglobin value below 65 per cent., and by examining the bone marrow if the red cells were not markedly hypochromic or if the patient had previously received iron therapy without improvement.

During the period of 14 months between January $195^{6}$ and February 1957 inclusive, 33 cases have been diagnosed. Six patients were admitted during the puerperium after being delivered at home or in another hospital and the other 27 patients were delivered in Whiston Hospital Maternity Department. The incidence during this period was one case in every 67 hospital confinements. The present report is concerned with the clinical, haematological and therapeutic features of these 33 cases.

\section{Clinical Features}

The age of the patients varied between 17 and 47 years and the mean age was 28 years. Ten patients were primigravidae and the mean number of previous pregnancies in the other 23 patients was 3 .

The haemoglobin level at the end of the preceding pregnancy was recorded in 8 patients. In 4 of these patients the haemoglobin level was low but the type of anaemia was not determined, and in I patient thcre was a definite megaloblastic anaemia.

The anaemia was detected during pregnancy in I 3 patients and in the puerperium in 20 patientso The earliest stage when the diagnosis was made was in the 3 Ist week of pregnancy, and the lates stage was seven months after confinement. In 14 patients the haemoglobin level was estimated initially within the first six months of pregnancy and at this stage the level was invariably above 70 per cent.

The obstetrical details were as follows. Two patients required Caesarean section for oblique lie and postmaturity respectively. Post-partum haemorrhage occurred in two patients, mild toxaemia occurred in one patient, and manual removal of the placenta was necessary in one patient. One patient had a stillborn baby, two patients had premature twins all of which died, and one patient had a hydrocephalic baby. In the remaining 23 patients, there were no obstetrical complications.

Lassitude and weakness were usual symptoms, although eight patients denied having any symptoms at all. Gastro-intestinal symptoms occurred o as follows: anorexia in 16 patients, vomiting in $N$ eight patients, and sore tongue in seven patients. N Pyrexia occurred in Io patients, and always settled within a few days of starting treatment. The spleen was palpable in only one patient. There were no abnormal neurological signs.

Many patients are unable to give an accurate account of their diet and it is often impossible to decide with any certainty whether a diet has an 
adequate folic acid content by questioning patients about their menu. Bearing these limitations in mind, a diet survey was made on 32 patients. The diet was assessed as adequate or good in 15 patients, and as poor in 17 patients.

One case in which the megaloblastic anaemia was associated with Addison's disease is described in detail below.

Case Report: A woman aged 3 I was admitted to Whiston Hospital on the I6th day of the puerperium. She gave a history of weakness and increasing pigmentation of the skin during the previous three years. During the last six months of pregnancy the weakness increased and she developed anorexia and vomiting. She had a normal delivery in another hospital, which she left against advice on the Ioth day of the puerperium. She had two other healthy children, aged $2 \frac{1}{2}$ years and I year respectively.

On examination her general condition was poor. There was pallor of the mucous membranes and marked pigmentation of the skin and oral mucosa. The blood pressure was $100 / 50 \mathrm{~mm}$. $\mathrm{Hg}$. There was no glossitis and the spleen was not palpable.

Investigations: Red blood cells, 2, 100,000 per cu.mm.; haemoglobin 34 per cent. (4.9 g. per I00 ml.); mean corpuscular haemoglobin concentration 33 per cent.; reticulocytes 8 per cent.; white blood cells 4,300 per cu.mm. (normal differential). Bone marrow megaloblastic. Serum sodium $122 \mathrm{mEq}$ per litre; serum chloride $9^{8}$ $\mathrm{mEq}$ per litre; serum potassium $3.8 \mathrm{mEq}$ per litre; blood urea $30 \mathrm{mg}$. per $100 \mathrm{ml}$. Urinary 17 -ketosteroids $1.54 \mathrm{mg}$. in 24-hour specimen. The consumption of 2 pints of water did not produce an hourly volume of urine in excess of the night volume of urine. Kepler factor 18 . The eosinophils in the peripheral blood disappeared after the intramuscular injection of $120 \mathrm{mg}$. ACTH gel. Radiographs of chest and abdomen were normal.

The diagnosis of Addison's disease was supported by the pigmentation of the skin and oral mucosa, the hypotension, the absence of a diuresis following the consumption of 2 pints of water, the low Kepler factor and the low level of the urinary I 7-ketosteroids. The response to the injection of $\mathrm{ACTH}$ is evidence that some functioning suprarenal tissue is still present.

Treatment and Progress. The anaemia was completely corrected after six weeks' treatment with folic acid, which was then discontinued. She was given Desoxycorticosterone acetate $3 \mathrm{mg}$. intramuscularly daily and Cortisone $12.5 \mathrm{mg}$. orally twice daily and the blood pressure rose to $130 / 80$ $\mathrm{mm}$. $\mathrm{Hg}$. on the $5^{\text {th }}$ day of this treatment. An implant of $200 \mathrm{mg}$. Desoxycorticosterone acetate was subsequently substituted for the daily intramuscular injections. Six months later the weakness returned, and her blood pressure fell to $1 \mathrm{IO} / 70$ $\mathrm{mm} . \mathrm{Hg}$. She was given another implant of 200 $\mathrm{mg}$. Desoxycorticosterone acetate and five months later the blood pressure was $140 / 80 \mathrm{~mm}$. $\mathrm{Hg}$. During the course of treatment, the pigmentation of the skin and oral mucosa has slowly cleared up.

\section{Laboratory Investigations Peripheral Blood}

The number of red blood cells varied between 0.7 and 3.3 million per cu. $\mathrm{mm}$. The average number of red blood cells was 2.74 million per cu. $\mathrm{mm}$. in the cases diagnosed during pregnancy and $\mathrm{I} .79$ million per cu. $\mathrm{mm}$. in the cases diagnosed during the puerperium. 'The haemoglobin values ( 100 per cent. $=\mathrm{I} 4 \mathrm{~g}$. per $100 \mathrm{ml}$.) ranged from 19 to 60 per cent. with a mean figure of 54 per cent. in the cases diagnosed during pregnancy and 40 per cent. in those cases diagnosed during the puerperium.

Anisocytosis with a predominance of macrocytes was usual, and the red cells were predominantly microcytic in only one case, in which the mean corpuscular volume was $7 \mathrm{I} \mathrm{cu}$. microns. In seven cases the red cells were hypochromic with a mean corpuscular haemoglobin concentration below 30 per cent. In the other cases the red cells were normochromic.

Megaloblasts were seen in the peripheral blood in only one case, in which the anaemia was the most severe in the series. An increased number of reticulocytes varying between 5 and 12 per cent. occurred in eight cases, and a small number of nucleated red cells were present in the peripheral blood in another four cases. Ten of the 12 cases with immature red cells in the peripheral blood were diagnosed initially during the puerperium.

The white cells numbered more than $1_{5}, 000$ per cu. mm. in two cases and less than 2,000 per $\mathrm{cu} . \mathrm{mm}$. in one case, but otherwise the numbers were within normal limits. A small number of immature white cells were seen in six cases, in five of which there were also immature red cells.

The serum bilirubin was estimated in six cases. In two cases the figures were raised to 1.5 and 2.5 $\mathrm{mg}$. per $100 \mathrm{ml}$. respectively, and in the other four cases the figure was below $0.8 \mathrm{mg}$. per $100 \mathrm{ml}$.

\section{Bone Marrow}

Marrow obtained by sternal puncture was examined in every case. Erythropoiesis was entirely megaloblastic in 14 cases, in most of which the anaemia was severe. In I9 cases there was both normoblastic and megaloblastic erythropoiesis, and the majority of the megaloblasts were 
transitional in type. The degree of megaloblastic erythropoiesis was related to the severity of the anaemia. A confident diagnosis could not be made from the appearance of the marrow in seven cases, in which the anaemia was relatively mild and erythropoiesis was mainly normoblastic with only very few transitional megaloblasts. In these seven cases, six of which were first observed during pregnancy, the diagnosis was confirmed by the response to folic acid therapy.

Macromyelocytes were a constant feature and we considered that they were of considerable diagnostic significance in those cases in which there vere only a few transitional megaloblasts.

\section{Gastric Acidity}

This was measured in 22 patients by the ' diagnex' method (Conway and Meikle, I953) and in two patients by fractional test meal. A histamine-fast achlorhydria was found in eight of the 24 patients. There appeared to be a relationship between the absence of hydrochloric acid in the gastric juice and the severity of the anaemia. In the eight patients with achlorhydria, the average haemoglobin value was 33 per cent., and the value was above 40 per cent. in only one patient. On the other hand, in the 16 patients with free hydrochloric acid in the gastric juice, the average haemoglobin value was 47 per cent., and the value was below 40 per cent. in only two patients. There was no opportunity to repeat the measurement of gastric acidity after correction of the anaemia in those patients with achlorhydria, but it seems probable that the achlorhydria is the result of the severe anaemia and not an aetiological factor.

\section{Treatment and Prognosis}

Eighteen patients were treated with oral folic acid, five patients were treated with oral folic acid conjugate (pteroyltriglutamic acid), and ro patients were treated with intramuscular vitamin $\mathrm{B}_{12}$. Three patients left hospital against advice before treatment was started. The effect of treatment was measured both by the reticulocyte response and by the subsequent rise in haemoglobin and erythrocytes.

\section{Vitamin $B_{12}$}

Treatment was started during pregnancy in five patients and during the puerperium in five patients. The total dose varied between 700 and $2,900 \mu \mathrm{g}$., and was given in divided doses of 100 $\mu \mathrm{g}$. daily for one to three weeks and then at twiceweekly intervals. There was a good response in seven patients. In one patient, who responded to treatment, a further specimen of bone marrow was examined two weeks after the onset of treatment and this showed that erythropoiesis had returned to normal.

There was no response in two patients after seven days' treatment. One of these patients was in the 7 th week of the puerperium and the other was in the $3^{6 \text { th }}$ week of pregnancy. Both patients responded subsequently to folic acid therapy.

In one patient, in whom treatment was started in the $34^{\text {th }}$ week of pregnancy. there was a reticulocyte response of 14 per cent. on the 9 th day of treatment but the haemoglobin value rose by only 5 per cent. during a period of four weeks. On changing to folic acid treatment there was a rapid improvement in the blood picture.

\section{Folic Acid}

This was the initial treatment in 15 patients, and it was given to a further three patients after treatment with vitamin $\mathrm{B}_{12}$ had failed. The dose varied between 20 and $30 \mathrm{mg}$. daily. Treatment was started during pregnancy in seven patients and during the puerperium in I I patients. The response to treatment was invariably good.

\section{Folic Acid Conjugate (Pteroyltriglutamic Acid)}

Treatment was started during the puerperium in four patients, and three days before delivery in the other patient. The total dose was $30 \mathrm{mg} 8$ given in three daily doses of ro mg. This treat? ment produced a good response in all five patients

\section{Iron}

In 16 patients there was a fall in the mean corpuscular haemoglobin concentration and the rise in the haemoglobin level either stopped or became very slow after the anaemia had been partially corrected by folic acid or vitamin $B_{12}$. Iron therapy rapidly increased the haemoglobin level in these patients.

It was impossible to follow up the progress of four patients for a sufficient length of time to decide whether iron therapy was required. Of the remaining $\mathrm{I} 3$ patients, seven had received iron before the onset of treatment with folic acid or vitamin $B_{12}$, and in six patients the anaemia was corrected without the administration of iron.

\section{Progress}

In view of previous experience that the anaemia does not return after stopping folic acid treatment (Forshaw et al., 1957), the patients in the present series were not followed up after the anaemia had been corrected. However, previous experience has shown that the anaemia tends to recur in subsequent pregnancies. In the present review, the anaemia has recurred in the only patient who has been observed during a subsequent pregnancy. 


\section{Discussion}

The incidence of megaloblastic anaemia of pregnancy and the puerperium is much higher than previous reports on the disease suggest. At Whiston Hospital during a period of 14 months the incidence has been one case in every 67 hospital confinements, which is over four times greater than the reported incidence at the Rotunda Hospital, Dublin (Lillie, Gatenby and Moore, 1954). The low incidence in previous reports is probably due to the diagnosis being often missed, and by careful investigation it has been found that the incidence at Whiston Hosiptal is three times greater than that reported previously (Forshaw et al., r957).

The diagnosis of megaloblastic anaemia should be suspected in women in the last trimester of pregnancy or the puerperium who have a haemoglobin value below 65 per cent. in the following circumstances: (I) When there has been a fall in the haemoglobin level of over 20 per cent. during pregnancy; (2) When the red cells are normochromic. Conversely, the presence of hypochromia does not rule out the diagnosis of megaloblastic anaemia; (3) When the patient has received regular iron therapy for several weeks without improvement.

In the majority of cases the diagnosis can be definitely established by examination of the bone marrow. The degree of megaloblastic erythropoiesis is usually related to the severity of the anaemia, and the appearance of the bone marrow is diagnostic in cases with a moderate or severe degree of anaemia. On the other hand, in the early stages of the disease when the anaemia is mild, it is sometimes very difficult to make a definite diagnosis on the appearance of the bone marrow. In the mild cases in which erythropoiesis is largely normoblastic, the presence of macromyelocytes in the bone marrow is of considerable diagnostic significance. When the bone marrow appearance is difficult to interpret, or when, as in domiciliary practice, it may be impracticable to examine the bone marrow, confirmation of the diagnosis depends on the response to folic acid therapy.

The belief that the majority of cases make a slow spontaneous recovery during the puerperium may lead to the opinion that the diagnosis is not of great importance. Our experience shows, however, that quite frequently there is a rapid deterioration during the puerperium. Sixty per cent. of the cases were diagnosed initially during the puerperium, and the degree of anaemia was considerably greater in those patients diagnosed in the puerperium than in those diagnosed during pregnancy. Immature red cells were seen more frequently in the peripheral blood of the patients diagnosed during the puerperium. It seems unlikely, however, that the presence of immature red cells in the peripheral blood was evidence of spontaneous recovery, as they were present in the blood of several of the most severely anaemic patients, who appeared to be deteriorating.

The efficacy of folic acid treatment has been well established (Thompson and Ungley, I95 I ; Davidson and Girdwood, I95I; Israëls \& Da Cuncha, 1952), and in our experience with a combined total of 37 patients in this and a previous series (Forshaw et al., I957) both folic acid and folic acid conjugate have produced invariably good results. Badenoch, Callender, Evans, Turnbull and Witts (1955) have found, however, that occasionally during pregnancy folic acid has not produced any response.

Early reports indicated that treatment with vitamin $\mathrm{B}_{12}$ was usually ineffective (Ginsberg, Watson and Lichtman, I950; Thompson and Ungley, I95 I ; Clark, I952) but the total dosage in the cases described did not exceed $120 \mu \mathrm{g}$. More recently, however, Moore, Lillie and Gatenby (1955) obtained a satisfactory response in 13 out of 17 patients by giving doses of between 460 and 5,000 $\mu \mathrm{g}$., and Adams (1956), in South Africa, obtained a satisfactory response in seven out of ro Indian and African patients with doses of between 100 and $\mathrm{r}, 400 \mu \mathrm{g}$. In Adams' series, all the patients who responded to vitamin $B_{12}$ therapy were in the puerperium, and the three patients who failed to respond were pregnant. We have given vitamin $B_{12}$ in divided doses up to a total of 700 to $3,000 \mu \mathrm{g}$. to 15 patients in this and a previous series (Forshaw et al., 1957) and in 12 patients there was a good response. Of the three patients who did not respond, two were pregnant and one was in the puerperium. There were no distinguishing clinical or haematological features in the patients who did not respond to vitamin $B_{12}$ therapy.

Megaloblastic anaemia of pregnancy is usually associated with iron deficiency, and practically 75 per cent. of our patients, who had not received iron prior to folic acid or vitamin $B_{12}$ therapy, subsequently required iron in order to correct the anaemia completely.

The aetiology of the disease still remains obscure. Dietary histories are often inaccurate, but they suggest that the diet was adequate in almost $5^{\circ}$ per cent. of this series of patients. Dietary deficiency of folic acid may be an aetiological factor in some patients, but, if this is the case, it is surprising that there is no clinical evidence of deficiency of other members of the vitamin $B$ complex. It has been suggested that defective folic acid metabolism may be an important aetiological factor (Mueller and Will, 
1955). If this thesis is correct, the large therapeutic dose of folic acid probably overcomes the metabolic defect by mass action.

Pregnancy is rarely met with in Addison's disease (Spence, 1953), and therefore one of our cases, in which megaloblastic anaemia of pregnancy was associated with untreated Addison's disease, is of particular interest. The maternal mortality in untreated cases is high, but in cases receiving cortisone therapy the prognosis is good (Singh, 1957).

\section{Summary}

The incidence of megaloblastic anaemia of pregnancy and the puerperium at Whiston Hospital during a period of 14 months was one case in every 67 confinements, which is considerably higher than the incidence in previous reports.

The diagnosis should be considered in anaemic women in the last trimester of pregnancy or the puerperium, if they have been receiving iron therapy with no improvement, if they were not anaemic in the early stages of pregnancy, and if the red cells are not hypochromic. The diagnosis can usually be established by examination of the bone marrow, but in mild cases the appearance of the bone marrow is sometimes very difficult to interpret. When the appearance of the bone marrow is not diagnostic, confirmation of the diagnosis depends on the response to folic acid therapy.

Treatment with both folic acid and folic acid conjugate has produced invariably good results. Vitamin $B_{12}$ has produced a good response in 12 out of 15 patients. There were no distinguishing clinical or haematological features in the three patients who did not respond to vitamin $B_{12}$ therapy. Iron therapy is also required in approxi- mately 75 per cent. of patients in order to completely correct the anaemia.

Diet surveys suggest that the diet was probably adequate in practically $5 \circ$ per cent. of the patients. Dietary deficiency of folic acid may be an aetiological factor in some cases, but there was no clinical evidence of deficiency of other members of the vitamin B complex.

One case in which megaloblastic anaemia of pregnancy was associated with untreated Addison's disease is described.

I wish to thank Dr. W. K. McGinley for his opinion on the bone marrow, Mr. W. N. Chisholm and Dr. N. Bennett-Jones for permission to study patients under their care, and Lederle Laboratories for supplying the pteroyltriglutamic acid.

\section{REFERENCES}

ADAMS, E. B. (1956), Brit. med. F., 2, 398.

BADENOCH, J., CALLENDER, S. T., and EVANS, J. R., TURNBULL, A. L., and WITTS, L. J. (1955), Brit. med. $\mathscr{F}$., I, 1245 .

CLARK, J. R. (1952), Edinb. med. F., 59, 274.

CONWAY, H., and MEIKLE, R. W. (1953), Brit. med. F., 2, 1019.

DAVIDSON, L. S. P., and GIRDWOOD, R. H. (I95I), Lancet, 2, 1193 .

FORSHAW, J. W. B., JONES, A. T., CHISHOLM, W. N., and McGINLEY, W. K. (1957), f. Obstet. Gynaec. Brit. Emp., $64,255$.

GINSBERG, V., WATSON, J., and LITCHMAN, H. (I950), F. Lab. clin. Med., 36, 238 .

ISRAELS, M. C. G., and DA CUNHA, F. A. L. (1952), Lancet 2, 214 .

LILLIE, E. W., GATENBY, P. B. B., and MOORE, H. C. (I954), Irish F. med. Sci., 6 th ser., 304 .

LOWENSTEIN, L., PICK, C., and PHILPOTT, N. (1955), Amer. F. Obstet. Gynec., 70, 1309.

MOORE, H. C., LILLIE, E. W., and GATENBY, P. B. B. (1955), Irish F. med. Sci., 6 th ser., 106.

MUELLER, J. F., and WILL, J. J. (1955), Amer. F. clin, Nutr., 3, 30.

SINGH, M. M. (1957), Brit. med. F., r, 503.

SPENCE, A. W. (1953), 'Clinical Endocrinology,' London: Cassell, 276

THOMPSON, R. B., and UNGLEY, C. C. (1951), Quart f. Med., 20, 187 .

An Address Book for the Medical profession, showing how to reach the various Colleges, Societies, Institutes and Hospitals in or near London

New (Fourth) Edition: 1954

Price 2s. 6d. (3s. Od., post free)

Published by the

FELLOWSHIP OF POSTGRADUATE MEDICINE

60 Portland Place, London, W.I 